\title{
LITERATURA Y REALIDAD HISTÓRICA. UN REENCUENTRO CON EZEQUIEL MARTÍNEZ ESTRADA Y SU INTERPRETACIÓN DEL MARTÍN FIERRO
}

\begin{abstract}
Rodríguez Amán Rosales, Literatura y realidad histórica. Un reencuentro con Ezequiel Martínez Estrada y su interpretación del "Martín Fierro". ["Literature and historical reality. A reencounter with Ezequiel Martínez Estrada's interpretation of the Martín Fierro”]. Studia Romanica Posnaniensia, Adam Mickiewicz University Press, Poznań, vol. XXXVII/1: 2010, pp. 27-42. ISBN 978-83-232-2145-6. ISSN 0137-2475. DOI 10.2478/v10123-010-0003-5.

The purpose of this paper is to critically review some of the main theoretical tenets in Ezequiel Martínez Estrada's pessimistic stance about the Argentinean history and society of his time. Focusing on his critical remarks about the so-called «literatura o poesía gauchesca» as well as on his enthusiastic assessment of José Hernández' Martín Fierro, the achievements and missing points in Martínez Estrada's skeptical diagnosis will be underlined and put in broader philosophical context. For the Argentinean writer the controversial notion of a "superimposed reality" -as he infers its existence from the Martín Fierro captures a kind of ambivalent metaphysical concurrence among the literary creation, the geographical setting and the sociopolitical state of the country.
\end{abstract}

Aunque no es posible afirmar que el ensayo literario goce hoy de la misma presencia, y ejerza la misma influencia que en el pasado en el contexto de la cultura hispanoamericana, no por ello resulta justo y prudente desconocer que su papel en la conformación del perfil intelectual y político de dicha cultura ha sido altamente significativo. Mucho antes de que la literatura de ficción convirtiese a un buen número de cuentistas y novelistas de la región en nombres familiares para lectores de prácticamente todo el mundo, el ensayo ya había demostrado la fecundidad de esa unión tan propia del género entre lo artístico y lo filosófico, lo imaginativo y lo reflexivo; en fin, de lo intuitivo y lo racional. No se olvide, por ejemplo, que mucho antes de La ciudad y los perros, Rayuela y Cien años de soledad, ya circulaban, generando controversias y discusiones, obras como Ariel, La raza cósmica y los 7 ensayos de interpretación de la realidad peruana.

Cada uno de esos clásicos del ensayo marcó un hito en la historia cultural del subcontinente. Los trabajos de Rodó, Vasconcelos y Mariátegui lograron crear en su 
momento, dentro de la ciudad letrada hispanoamericana, una atmósfera intelectual dotada de un vigoroso sentido de comunidad cultural. En vista del noble pasado del género, resulta lamentable constatar la poca familiaridad que sugieren en la actualidad apellidos como Sanín Cano, Picón Salas o Martínez Estrada -de hecho, incluso en círculos de los que cabría conjeturar mayor conocimiento de la literatura de ideas hispanoamericana-. Pues, si bien en el caso de lectores cultos pero no especializados lo anterior se puede considerar, hasta cierto punto, explicable, resulta inexcusable entre quienes se dedican al estudio serio y sistemático de la literatura hispanoamericana -o literatura en lengua española sin más-.

Un caso que merece reconsiderarse es el del autor de textos semi-olvidados o descuidados en el presente, como Radiografía de la pampa, La cabeza de Goliat y Muerte y trasfiguración de Martín Fierro. Se trata el escritor argentino Ezequiel Martínez Estrada (1895-1964), ante cuya obra y persona la crítica especializada parece estar dividida, dicho sea no necesariamente de paso, de un modo mucho más radical que en otros $\operatorname{casos}^{1}$. Cuando Martínez Estrada publica la primera edición de Muerte y trasfiguración de Martín Fierro (1948) -obra que concentra el interés del presente trabajo-, su trayectoria literaria estaba suficientemente consolidada. La producción del santafesino, sobre todo la poética, iniciada en su temprana juventud, había sido objeto de diversos e importantes reconocimientos por parte del medio cultural y literario $\operatorname{argentino}^{2}$.

Por lo demás, la biografía de Martínez Estrada muestra que su posición en el ambiente literario argentino estaba lejos de constituir sin más -como él mismo lo quiere dar entender a veces- la de una suerte de écrivain maudit ${ }^{3}$. Tanto más extraña,

${ }^{1}$ Considérese solo dos ejemplos de la acogida positiva a su obra: «Observador minucioso e implacable, fino analista de la psicología nacional, Martínez Estrada maneja un estilo de gran riqueza metafórica, notable sutileza lingüística y calidad poética excepcional». Con esas palabras lo juzgó R.G. Mead Jr. (1956, p. 119) J. Skirius se expresó en forma igualmente favorable sobre Martínez Estrada: «La originalidad literaria y la pasión intelectual de su crítica avasalladora obligan a calificarlo como uno de los ensayistas hispanoamericanos más importantes del siglo XX» (2004, p. 191). Respecto de la tendencia crítico-negativa pueden mencionarse los trabajos de Rivera (1987) y Sebreli (2007). En este lugar se omiten ilustraciones de estos dos últimos -importantes- estudios por cuanto serán citados más adelante.

${ }^{2}$ En 1933 había recibido el Premio Nacional de Literatura y en 1937 el Premio Nacional de Letras por su Radiografía de la pampa -aparecida cuatro antes-. Asimismo, en 1947 obtuvo el Gran Premio de Honor de la Sociedad Argentina de Escritores (S.A.D.E.). En 1950 fue nominado por Carlos Erro, entonces presidente de la S.A.D.E., nada menos que al Premio Nóbel. Vale la pena recordar también que con antelación a los dos volúmenes de Muerte y transfiguración, Martínez Estrada había dado a la imprenta varios de sus trabajos ensayísticos más importantes, como La cabeza de Goliat. Microscopía de Buenos Aires (1940), Sarmiento (1946) y Los invariantes históricos en el Facundo (1947), a los que seguirían El mundo maravilloso de Guillermo Enrique Hudson (1951), El hermano Quiroga (1957), Heraldos de la verdad. Montaigne, Balzac, Nietzsche (1958), y Cuadrante del pampero (1959), entre otros textos que refrendan la productividad del polígrafo argentino.

${ }^{3}$ Esta afirmación se apoya, en forma parcial, en el juicio del crítico más inclemente de Martínez Estrada. Según J.J. Sebreli, aquél cultivó a lo largo de su vida una posición personal básicamente 
por ende, el inconfundible tono de desesperanza y pesimismo cultural -influido por pensadores como Schopenhauer, Nietzsche y Spengler-que para muchos identifica al estilo estradiano. De hecho, cosa que también causa sorpresa -aunque solo a primera vista-, dicha vena en extremo desencantada sobre la realidad nacional no entró en conflicto con aquel desbordante entusiasmo experimentado por Martínez Estrada en los últimos años de su vida hacia la Revolución cubana. En efecto, su personalísima «experiencia cubana» ${ }^{4}$ desbordó límites y reveló, o por lo menos clarificó mejor tanto ciertos rasgos de la personalidad del autor argentino como de su más bien enmarañado pensamiento político. Se volverá sobre este tema al final del trabajo.

Precisamente, en sus casi novecientas páginas, Muerte y transfiguración de Martín Fierro -obra que cabe ubicar, por la calidad de su prosa, por lo menos en el mismo escalafón que su más conocida Radiografía de la $p_{a m p a}{ }^{5}$-, representa tanto un aporte fundamental a los estudios interpretativos sobre el poema de José Hernández ${ }^{6}$, como, a la vez, una especie de gigantesca suma del pensamiento estradiano. Empero, si bien son varios los temas de interés que traslucen en el texto, hay uno que también aparece y reaparece con persistencia obsesiva en el resto de la ensayística estradiana; a saber, el de la relación entre literatura e historia, o, más en concreto, el de la interpenetración o interdependencia entre la creación literaria o poética y la auto-representación o autorecreación histórica por parte de una nación.

ambivalente: «En esa ambivalencia Martínez Estrada logró una trayectoria intelectual zigzagueante pero siempre afortunada; nunca estuvo en el centro de la élite de las letras pero tampoco fue un marginado, como gustaba proclamarse y sus admiradores siguieron repitiendo» (2007, p. 28).

${ }^{4}$ La expresión hace referencia al volumen Mi experiencia cubana, publicado en Montevideo en 1965. El título original de esa obra es aún más explícito: En Cuba, y al servicio de la revolución cubana (La Habana, 1963).

${ }^{5}$ Obra de la que Muerte y transfiguración, aunque escrita quince años más tarde, constituiría, en palabras de su propio autor, una especie de preámbulo. Martínez Estrada escribe incluso que esas dos obras, más El mundo maravilloso de Guillermo Enrique Hudson, conforman una trilogía, «un estudio etnológico, histórico y antropológico de la República Argentina en su complexión constitucional» (II, p. 439).

6 Tan solo de este aspecto, J.M. Oviedo ha dicho acertadamente que se trata de «un estudio exhaustivo, acucioso y hasta maniático en sus detalles, que todavía hoy es válido y con pocos rivales que se puedan comparar como una gran obra maestra de devoción y erudición» (1991, p. 87-88). Puesto que el objetivo restringido de este trabajo es examinar algunas de las consecuencias históricas del poema de Hernández, desde solo una de las aristas teórico-filosóficas más significativas presentes en el estudio de Martínez Estrada -la que se revela en la noción de una «realidad superpuesta»-, no se considerará el tema de la validez propiamente dicha de la interpretación estradiana en el contexto de la larga historia de recepción crítico-comparativa -con su amplísima bibliografía- del Martín Fierro. A este respecto puede consultarse con provecho el ensayo de Ángel Rama, aún actual, «El sistema literario de la poesía gauchesca» (véase Rama 1977). Por último, al releer el juicio borgiano sobre el Martín Fierro, en el conocido ensayo sobre la poesía gauchesca: «Sospecho que no hay otro libro argentino que haya sabido provocar de la crítica un dispendio igual de inutilidades» (1997, p. 38-39), no cabe sino subrayar que Muerte y trasfiguración de Martín Fierro, obra excepcional por su audacia y perspicacia interpretativas, representa justamente lo opuesto de lo expresado por Borges. 
Pero incluso ese tema fundamental adquiere todavía en Muerte y transfiguración un desarrollo más específico y preciso a partir de la idea estradiana de una «realidad superpuesta»; es decir, una realidad que, inventada desde el texto literario, comienza por condensar y recrear, para luego trastornar y finalmente reemplazar, la realidad del mundo histórico. El tratamiento de esta cuestión, que confiere al texto de Hernández una insospechada pero ambivalente dimensión metafísica, a tono en todo caso con la en extremo pesimista lectura estradiana - «radiográfica»-de las pampas, constituye una especie de justificación filosófica de la propia crítica radical estradiana a la evolución de la literatura y la sociedad argentinas, antes y después de la aparición de la llamada «literatura o poesía gauchesca». El presente trabajo centra buena parte de su atención en presentar e intentar clarificar el significado y (algunas de las) repercusiones de la idea de una «realidad superpuesta», noción que extraída del poema de Hernández, constituye, para subrayarlo de nuevo, un ingrediente fundamental de lo que puede considerarse un proyecto de lectura metafísica de la realidad histórica argentina por parte de Martínez Estrada.

El «ensayo de interpretación de la vida argentina» que Martínez Estrada esboza en su Muerte y transfiguración, no puede separarse de su autopercepción como escritor e intelectual. Esta autoimagen se liga, en el caso del santafesino, a la íntima relación de parentesco biográfico e intelectual que insinúa o propone entre ciertos aspectos de su vida y la de José Hernández (1834-1886). Ya que, a pesar de la declarada hostilidad estradiana hacia las especulaciones biográficas ${ }^{7}$, no cabe duda de que el mismo Martínez Estrada deja entrever importantes paralelismos entre su trayectoria intelectual y la del autor del Martín Fierro. De hecho, cabe proponer que, precisamente porque Martínez Estrada niega de forma expresa la pertinencia de la «mera» lectura semiautobiográfica del poema de Hernández, en esa misma medida y proporción -actitud típicamente estradiana- señala a la importancia y valor de la dimensión biográfica como una de las claves interpretativas del carácter y significado individual y colectivo (nacional) de la obra literaria.

Martínez Estrada parece hablar de sí mismo cuando afirma que es posible establecer un nexo fundamental entre la vida del autor y su obra; es decir, no resulta improcedente sino, todo lo contrario, considerar «al Autor como un ente sometido, por razones ignoradas, a su propia soledad; y al Poema como un ente sometido, también

\footnotetext{
7 Véase el comienzo de su «Carta a Victoria Ocampo» (1945): «Al fin y al cabo, cuanto aconteció en mi existencia tiene poca relación casual, lógica, conmigo. Parezco ser un ente que atravesó ileso e inmune los hechos que constituyen su existencia terrestre, humana, diaria, documental. Nada tengo que ver con mi biografía. Repasado el texto, siento que vivir y ser son dos realidades distintas».
} 
por razones misteriosas, a su propia soledad» (I, p. 12) ${ }^{8}$. Esto quiere decir «que esos dos destinos, el de Martín Fierro y el de José Hernández, están ya unidos por algún signo que ha de serles común, hasta el extremo de poder pensarse que precisamente las causales que determinaron la soledad y el silencio en torno al Autor, pueden ser las mismas que originaron la creación de su Obra» (I, p. 12).

Otras aseveraciones dispersas en Muerte y transfiguración suenan como quejas del propio autor hacia su entorno social; como cuando pone a Hernández en el papel de un Hércules hilando en la rueca de Onfalia, es decir, nada menos que como el semidiós abocado a faenas indignas de su poder. Pero también Martínez Estrada se atreve a parangonar a Hernández con el autor de la Divina Commedia: «Hernández era mucho más de lo que alcanzó a ser. Y no fue más porque mucho tiempo erró por la selva oscura en que tantos se extravían, y porque nada a su alrededor lo alentaba a proponerse una obra de mayor aliento. La comparación con Dante está dentro de lo lícito en el plano de las esencias: Dante, el Poeta, fue también así» (I, p. 38).

Es lícito ver en el retrato que Martínez Estrada pinta de José Hernández en las primeras páginas de Muerte y transfiguración una protesta, poco disimulada por cierto, en contra del supuesto estado de marginación en que él mismo se encontraba dado su papel de crítico implacable -orgullosamente autodidacta- de la sociedad argentina y su cultura oficial. Opera aquí sin duda una estrategia característica de la retórica estradiana cuyo objetivo final no es otro que el de suscitar simpatía tanto hacia lo que se ofrece como el heroico esfuerzo de un sacrificado autor, como, cosa aún más difícil de alcanzar, hacia la innegable necesidad de complicidad respecto de una crítica social avasalladora, cuyas intransigentes pretensiones de totalidad tenderían, más bien, a ahuyentar a los espíritus moderados. Esto permite formarse una idea de la compleja posición personal y literaria estradiana en el contexto de la sociedad argentina de su tiempo.

La presentación que de sí mismo hace Martínez Estrada como un autor marginado por el oficialismo gobernante, parece alimentarse del mismo urgente deseo -a la postre irrealizable- de ser aceptado como el guía espiritual y moral de la nación. En su autoimagen como intelectual incomprendido, socialmente desaprovechado, Martínez Estrada advierte cierta similitud con José Hernández, quien también «era un hombre, si no conforme con las cosas del país, fuera de la orientación de quienes querían mejorarlo mediante la educación cívica creando una alta cultura en las letras, las ciencias y las artes» (I, p. 48). Martínez Estrada junta su destino personal con el de Hernández al reiterar que a los «heraldos de la verdad», a los denunciantes honestos de la barbarie y la mediocridad, solo les tocará como destino la soledad, el destierro interior o el exilio exterior:

Creo ver cumplirse, también en Hernández, esa ley terrible de nuestra historia que exige el sacrificio humano en pago de la gloria. Cualquier excelencia despierta la hostilidad, que desde

${ }^{8}$ En lo sucesivo toda cita de esta obra en el cuerpo del trabajo se tomará de su segunda edición corregida (1958), indicándose el número de tomo y la página respectiva. 
el centro de los seres más queridos se propaga hacia la periferia. Todo grande hombre está solo, y el movimiento de sístole que protege al incapaz expulsa en vigorosa diástole al bien dotado por Dios o por la naturaleza, particularmente al benefactor. Nuestros más grandes hombres han muerto en el destierro, dentro o fuera del país. (I, p. 44) ${ }^{9}$

La significación trascendente que Martínez Estrada otorga a la idea de un llamado personal, a una especie de vocación misional del intelectual, desde luego que se complementa con lo que él concibe como la trascendencia de la «Obra»-es decir, de ciertas «Obras»-, en este caso, del Martín Fierro. Este texto representa para Martínez Estrada no solo la culminación y superación a la vez de la «poesía gauchesca», tal y como venía practicándose hasta 1872 -año de publicación de la primera parte-, sino y sobre todo la confirmación indiscutible de su propio sombrío diagnóstico de la existencia social argentina (humana en general) en su anterior Radiografía de la pampa. De ahí que Martínez Estrada abogue por el rescate de la obra de su propia fama como símbolo por antonomasia de la nacionalidad, y que se reconozca su auténtica valía como documento realista a ultranza de la condición humana.

Ajuicio de Martínez Estrada, la extrema popularidad del Martín Fierro, su manoseo académico, y su elevación final al podio de lo folclórico por excelencia del espíritu nacional argentino, han terminado por ocultar su mensaje históricamente invariante, más hondo y deprimente que el literal. Porque es verdad, según la versión estradiana, que el Martín Fierro define lo argentino, pero no al modo triunfal y engañoso en que los críticos, académicos y lectores superficiales lo enseñan y entienden. Su mensaje esencial concierne no solo - de hecho casi solo en último término- a las vicisitudes existenciales de su protagonista principal, sino y sobre todo a la profunda realidad histórica de lo gauchesco que, tomado en su circunstancia histórica y social, alude a modos de vivir y sufrir comunes a todos los seres humanos en circunstancias similares:

La realidad histórica es un concepto más amplio y central que cualquier otro; se forma con los invariantes que a través de los siglos perpetúan a un pueblo como tipo de raza, de misión, con su fisonomía y su némesis. Todo lo demás es un aderezo, y sólo mediante la observación atenta de esas líneas tectónicas un pueblo es un organismo inmortal que persevera dentro de máximas y mínimas, tanto vitales como formales: tiene un ethos, un rostro, un sino. (II, p. 203)

Para Martínez Estrada, la trivialidad de lo biográfico-anecdótico en el poema de Hernández constituye una prueba de que la valía real de la obra reside no en el escudriñamiento psicológico de Fierro, sino en su papel de símbolo de ciertas manifestaciones de lo humano en sus límites existenciales. En los versos del Martín Fierro se revela una trágica «sustancia» universal -que se materializa en el caso

${ }^{9}$ Martínez Estrada confesó, en una obra posterior, que pensaba en Horacio Quiroga y en Leopoldo Lugones al escribir esas palabras sobre Hernández y el destino de los grandes hombres. Sobre Quiroga, dice, en efecto: «Su ejemplo me ha valido para explicarme la soledad de las alturas, el frío de las cumbres, y me ha servido para fortalecerme y sobrevivir de mis propias reservas» (1995, p. 83). 
argentino en la pampa como lugar de desolación geográfica y existencial- que desborda lo epidérmicamente novelesco -más bien pobre según Martínez Estradade su trama escrita. Sin que su autor se lo propusiera, el poema de Hernández quitó la máscara embellecedora que la «literatura gauchesca» anterior había puesto sobre la «realidad pura» de la historia argentina, revelándola en toda su crudeza. Según la lectura de Martínez Estrada, el poema encarna integralmente el paisaje pampero, reúne en sí aquellas «características físicas, somáticas, de esa matriz que se llama la pampa, la soledad, la pobreza, la injusticia». A su vez, el personaje Martín Fierro es «un elemento para reconstituir un ambiente, porque ese ambiente se ha hecho persona en él y puede cambiar constantemente de aspecto pero no de sustancia. Martín Fierro es lo invariante, lo permanente de un sino regional, estructural, social» (I, p. 76).

En la obra literaria de rango artístico universal -y claramente el Martín Fierro entra, según Martínez Estrada, en esa categoría- convergen dos fuerzas poderosas: la del artista, creador individual, y la de un destino telúrico superior que logra expresarse a través del primero. Se trata para Martínez Estrada, siguiendo intuiciones de Hermann Keyserling, -autor de las, en su momento, influyentes Südamerikanische Meditationen (1932)-, de una determinación histórico-metafísica más profunda, una especie de hado originado en el medio geográfico argentino y que encontró en el individuo José Hernández, su medio idóneo de enunciación poética. Así, el significado geológico-metafísico profundo del Martín Fierro está más allá de toda duda para Martínez Estrada:

Se percibe en el Poema que actúan las fuerzas activas, plásticas, de la geografía y de la historia, que lo adjetivo es lo real y lo sustantivo lo eventual. Lo que ha producido la aventura de Martín Fierro es la misma mano que ha modelado nuestras instituciones, nuestra cultura, nuestra idiosincrasia. Hernández es, como Martín Fierro, un evento. Es lo que ha elevado grandes ciudades y destruido grandes almas. (I, p. 339) ${ }^{10}$

\section{III}

«El Martín Fierro es una realidad superpuesta. La realidad es obliterada por esa visión literaria, las cosas se evocan a través de sus versos» (I, p. 284). ¿Qué significa esta afirmación en el contexto de Muerte y transfiguración? Ante todo expresa que la realidad poética descrita en el texto llamado Martín Fierro acaba suplantando la realidad real, la misma de la que habría partido la obra de Hernández. Dicho de otro

${ }^{10}$ El significado central que tiene el fatalismo telúrico en el pensamiento estradiano ha sido examinado de cerca y de forma convincente por Sebreli, su conclusión reza: «El fatalismo telúrico de Martínez Estrada y sus derivados -el "pecado original" de H.A. Murena, el "demonio americano" de F.J. Solero, el "demonismo vegetal" de Rodolfo Kusch, el "desarraigo argentino" de Julio Mafuderan, a pesar de la variedad de ideologías, la expresión inconsciente del pesimismo irracionalista de una sociedad que se negaba a reconocer las causas concretas de su decadencia y prefería pensar que era el mundo moderno el que decaía» (2007, p. 77). 
modo, el escrito -concebido inicialmente como documento de denuncia social- acabó apoderándose, merced a un proceso que en la narración de Martínez Estrada no queda del todo claro, de lo documentado, al extremo de que despertó en la nación argentina un acrítico y exaltado entusiasmo por sus figuras y gestas históricas y literarias, pero a la vez la tornó más insensible hacia los hechos verídicos de injusticia y miseria poetizados por Hernández. El deseo de Hernández era «no desfigurar, no disimular, no encubrir» (II, p. 196), mas al final su obra fue usada precisamente para eso. De ahí también la curiosa pero de nuevo trágica ambivalencia del texto en el desarrollo de la «literatura gauchesca» y argentina en general: en lo poético/literario constituye su cumbre insuperable mas también su liquidación definitiva -coadyuvado por epígonos que según Martínez Estrada empobrecen y rebajan su mensaje-.

Al elevarse a la categoría de Poema supremo de la nación -tanto para los simpatizantes como para los detractores del gaucho y lo gauchesco-, el Martín Fierro vuelve invisibles, a juicio de Martínez Estrada, los hechos brutos de iniquidad y violencia que suscitaron originalmente la indignación del poeta. De este modo, la «realidad pura» develada por el poema queda obstruida, investida de la dudosa categoría de épica patriótica. Hernández, en cierta forma indefenso ante la vida propia adquirida por su alter ego ${ }^{11}$, y como triste compensación de su metamorfosis en instrumento de su Payador, no alcanza a reaccionar de otra forma más que asumiendo el papel de simple narrador que sermonea, en las "Cuatro palabras de conversación con los lectores", sobre la necesidad de dar al pueblo obras de edificación cristiana, moral, y sobre la integración social del gaucho.

En realidad, Hernández habría actuado de cómplice involuntario, de acuerdo con la interpretación estradiana, de aquella infame alianza explicitada así por Ángel Rama: «Un magno pacto dentro de la sociedad nacional quedaba así diseñado: la clase superior aceptaría la ruda poesía popular y su cosmovisión, la haría suya, la protegería, a cambio de que la clase inferior (los gauchos, que según Lugones habían sido los edificadores de la nacionalidad) reconociera que debía ser conducida por los cultos» (1977, p. XXI) Con arreglo a la lectura de Martínez Estrada, la lectura patriótica del Martín Fierro redujo su significado profundo de invariante histórico al de adorno oportuno para hueras festividades nacionales ${ }^{12}$. Se trata del mismo proceso de mistificación que ha impedido la consolidación de una literatura nacional

11 Según parece, el mismo José Hernández era conocido entre sus amigos como «Martín Fierro».

12 Martínez Estrada se expresa así de la relación entre literatura y patriotismo: «¿Qué es lo que impide entre nosotros que el escritor y el lector vayan rectamente a esa vida y a ese almácigo de vida sin disfraz y sin oropeles? Pues saben ustedes que también el lector estraga al escritor, como el pueblo al político. Se lo impide a ambos un sentimiento respetable si es sano, y altamente vituperable si es enfermizo o vacuo. Ese sentimiento es el patriotismo. El patriotismo constituye sobre todo en Hispanoamérica un género literario extenso, profundo y voraz. Es como ciertos yuyos de raíz extensa, profunda y voraz. Devora y marchita el patriotismo enfermizo o vacuo cuanto cubre, como yuyo y como planta parasitaria que vive a expensas de otras» (1956). 
argentina, aquello que pudo ser y no fue, aquello que el Martín Fierro pudo haber iniciado pero que, paradójicamente, más bien canceló. Porque con esa obra «la literatura gauchesca termina. Era un principio y sin embargo fue un fin» (I, p. 284) Desde entonces, según el santafesino, la literatura argentina no existe como expresión auténtica de la vida profunda de la nación sino como manifestación de una engañosa autocomplacencia ${ }^{13}$.

La «literatura gauchesca» degeneró entonces, como resultado de la «mitificación de Martín Fierro en héroe de cuchillo», en «caricatura grotesca». Dado que Fierro «no podía ser destruido en su ley», había que cargarlo, insiste Martínez Estrada, «de una investidura heroica, hacer de él un dechado de coraje, altivez, hidalguía. No podía permitírsele su existencia real, sino que era preciso hipostasiar fama y gloria, es decir, transferirlo al plano de la admiración patriótica en calidad de variante correlativa del héroe» (I, p. 296) Ese héroe de ficción fue entregado al pueblo para su entretenimiento nacionalista y admiración fervorosa: «De donde podemos decir que para matar a Martín Fierro, que era un testigo impertinente, hubo de destruírselo por su conversión en mito heroico y patriótico» (I, p. 299) ${ }^{14}$.

La idea de que del poema de Hernández constituye una clase especial de realidad autónoma; esto es, independiente en gran medida de la voluntad de su creador $-\mathrm{y}$ sus cambiantes actitudes ante ella-, se apoya en la firme convicción estradiana de que en las grandes obras del arte y la literatura actúan poderosas fuerzas físico-metafísicas que brotan incontenibles en determinados momentos de la historia de un pueblo. De ahí que el fenómeno de la superposición de la realidad literaria sobre la realidad histórica no le resulte a Martínez Estrada una ocurrencia metafísica extravagante. Al contrario, la creación literaria concita, en su opinión, ciertos impulsos vitales que nacen del paisaje natural, la tierra, y mental, la psique popular. Lo gauchesco, en

${ }^{13}$ En la misma conferencia anterior Martínez Estrada se refiere a la relación entre literatura y vida social: «La literatura no sólo debe ser reflejo fiel de la vida de un pueblo sino el órgano de penetración en las entrañas de la tierra y del habitante, el vínculo de solidaridad y simpatía, la argamasa de la solidaridad humana que empieza por la solidaridad familiar» (1956).

${ }^{14}$ Según Martínez Estrada, el desprecio abierto por el gaucho se remonta, en la historia del país, por lo menos, a los tiempos del prócer argentino Domingo Faustino Sarmiento -de quien José Hernández fuera, por cierto, encarnizado enemigo político-, quien veía en la fuerza gauchesca bajo el mando de caudillos regionales (como Juan Facundo Quiroga) una manifestación de barbarie. En efecto, sobre la «montonera» gauchesca acaudillada por el líder independentista José Gervasio Artigas, asevera Sarmiento que sus consecuencias son similares a la de una incontenible y destructora fuerza natural, al modo de un poderoso tornado que lo arrasa todo a su paso: «¡De este instrumento se sirvieron los partidos diversos de las ciudades cultas, y principalmente, el menos revolucionario, hasta que andando el tiempo, los mismos que lo llamaron en su auxilio sucumbieron, y con ellos, la ciudad, sus ideas, su literatura, sus colegios, sus tribunales, su civilización!» (1977, pp. 66-67). Por doquier se citan las siguientes palabras -tristemente célebres- de Sarmiento, tomadas de una carta de 1861 al presidente Mitre: «No trate de economizar sangre de gauchos. Este es un abono que es preciso hacer útil al país. La sangre es lo único que tienen de seres humanos» (Citado por L. Sáinz de Medrano en Hernández, 2007, p. 20). 
particular, representa, desde la perspectiva estradiana, una cualidad, o mejor una invariable sustancia histórico-individual que determina de una vez y para siempre, ya sea ocultándolo o haciéndolo visible, el verdadero carácter del país. Sobre lo gauchesco como expresión sustancial, correspondiente a un invariante histórico destinado al pueblo argentino, se expresa así, en síntesis, Martínez Estrada:

En los trastornos del proceso de formación de la vida entera del país -en lo ético, económico, religioso, conductista, pragmático- [lo gauchesco] es una "toma" vivencial, un modo de ser las gentes; y eso queda firme a través de las vicisitudes de los cambios políticos, de las técnicas industriales, del aprovechamiento de los productos naturales y de cultivo, de la enseñanza y de la obra de gobierno. Es lo que queda cuando todo cambia. (I, p. 277)

\section{IV}

La visión de mundo que José Hernández comparte con sus lectores es, según la lectura de Martínez Estrada, francamente desalentadora. El universo de Fierro es un lugar de aciagas experiencias, un territorio sombrío, escenario «de un acontecer trágico e ineluctable», signado por una «crueldad absurda» que pareciera inspirada en parte por el Canto XXXIII del Infierno dantesco (I, p. 219) ${ }^{15}$. No es de extrañar que en un arrebato de pesimismo poético extremo, Martínez Estrada se sienta cómodo contemplando a la humanidad toda desde la lúgubre perspectiva que le ha revelado el Martín Fierro:

Sabemos, pero ni siquiera lo queremos pensar, que esos crímenes son cometidos por entidades abstractas, por divinidades informes: el Estado, la escala de las autoridades, los vicios la deficiente educación, la avaricia, la concupiscencia, la organización económica, las epizootias y las plagas vegetales, la falta de dignidad en la conducta, la ley de los declives, que es caer, rodar, descender [...] No me refiero ahora a la Argentina exclusivamente; con motivo del Martín Fierro puedo cómodamente entrar a juzgar a sí a las naciones todas, a todos los Estados constitucionales, a las sociedades en el nivel de la mínima civilización, y a la historia humana en bloque. (II, p. 410)

En opinión de Martínez Estrada, el poema de Hernández reproduce con fidelidad lo irreparablemente defectuoso de la idiosincrasia argentina, o lo que él llama, la «doctrina» argentina en sus dimensiones filosófica, social y política. Dicho carácter nacional está marcado, entre otros rasgos, por «el descontento, la mortificación, el encono sin poder concretar qué es lo que se quiere (aunque mejor se concreta lo que no se quiere)» (I, p. 236).

En efecto, en la Argentina, agrega Martínez Estrada: «Nadie sabe qué es lo que ocurre ni cómo remediarlo» (I, p. 236). Tal es la constatación primordial que es preciso aceptar de previo a cualquier interpretación crítica del poema. Y esa es, igualmente, la

${ }^{15}$ Recuérdese las palabras con que el Hijo mayor describe la penitenciaría en La vuelta de Martín Fierro: «Inora el preso a qué lado / se inclinará la balanza; / pero es tanta la tardanza, / que yo les digo por mi: / el hombre que dentre allí / deje afuera la esperanza» (Hernández, 2007, p. 254). 
conclusión -aunque formulada con otras palabras y apoyada en otro tipo de estrategias argumentativas-, a la que había arribado Martínez Estrada quince años antes de la primera edición de su estudio del poema. Pero incluso mucho antes, en su Radiografía de la pampa, ya el autor se había explayado en los rasgos de falsedad, ocultamiento, disimulo, solapamiento, etc. que presenta la sociedad argentina desde sus inicios como república independiente.

Pero de nuevo se presenta aquí la paradoja que acompaña al diagnóstico estradiano: ese mundo de adversidades y atrocidades al que tiene que enfrentarse Fierro, descrito por Hernández, aunque inspirado en el mundo real, termina por falsearlo en la medida en que de su mensaje se extirpa el contenido brutal pero verdadero que señala a los fallos estructurales de la sociedad, y se asume solo su mensaje de barbarie poéticamente domeñado. La popularidad del texto rubrica, según la versión estradiana, el proceso de embellecimiento/falseamiento de la realidad social argentina. Ahora bien, pero de un modo paradójico que afecta a la lectura estradiana -aspecto que se extrae de ella en forma inmanente-, habría que agregar que lo que en apariencia son dos destinos paralelos pero incomunicados, el poético y el real, convergen en uno, y esto pese a la cruda separación establecida finalmente por Martínez Estrada entre lo que el Poema narra y lo que viven los habitantes del mundo real. Pues aquel destino atroz que acaba por atrapar y arrojar a los personajes del poema de Hernández al último círculo de indiferencia, soledad y sufrimiento es, en realidad, para Martínez Estrada, el mismo que mantiene al país sureño en otra clase de sueño, no menos absurdo, carente de sentido como proyecto viable de nación.

Desde la perspectiva estradiana puede afirmarse que las clases dirigentes argentinas tuvieron éxito en su estrategia decorativa o encubridora de la historia del país. Dicho falseamiento embellecedor de la realidad se sirvió de la «literatura gauchesca» como medio homogenizador de la conciencia nacional. Aunque su mensaje iba dirigido no al embellecimiento sino al develamiento de la «realidad pura», el Martín Fierro se convirtió/fue convertido en el principal aliado de aquella estrategia, con la que varios autores menores, en el contexto de la «literatura gauchesca», se sintieron patrióticamente identificados. El resultado final, presente, del proceso de superposición de la realidad poética sobre el acontecer histórico lo sintetiza así Martínez Estrada: «Se defiende ahora una realidad embellecida por la poesía y por una historia ornamental, de una sensibilidad de inmigrante afortunado, de burgués conforme con su suerte» (1993, p. 21).

Meditando sobre dicha tarea de suavización o liquidación de conflictos, Martínez Estrada concibió la idea de que el Martín Fierro había desempeñado, nolens volens, un papel primordial en la historia y literatura argentinas. Pero se trató de un papel oscurecido por una trágica ambivalencia. El mundo literario del payador se superpuso al mundo real y éste, en adelante, ya no se pudo -o no se quiso- percibir más en toda su brutalidad. La ficción ocultó a la realidad que le había servido de inspiración. El Martín Fierro al descubrir la realidad de inmediato echó un velo sobre ella. Incluso 
más, la sustituyó erigiendo su propia versión literaria. Uno tan solo de los numerosos problemas irresolutos que deja la situación anterior de autocomplacencia y autoengaño sobre la herencia histórica consiste, para el ensayista argentino, en que el país nunca supo en realidad qué hacer con el «problema indígena» que se suponía «liquidado» -en lo militar y lo político-con la consumación de la tristemente célebre Conquista del Desierto -y la nación argentina «rescatada» de la amenaza de «barbarie»-. Martínez Estrada opina que dicha actitud triunfalista carece de todo fundamento:

La venganza más terrible del indio -su victoria- ha constituido en dejarnos habitar un mundo sin indulgencia para los miserables, sin delimitación precisa entre lo justo y lo injusto, lo digno y lo indigno, el poder y el derecho, lo auténtico y lo apócrifo. Mundo que por no haber tenido conciencia del problema del indio ahora se debate sin encontrar solución a sus "problemas indígenas". Mundo sin poesía y sin realidad, sin otro pasado que el que se ha hecho para vivir sin cargos de conciencia y sin necesidad de mirar de frente su imagen verdadera. (II, p. 94) ${ }^{16}$

Ante el deprimente panorama trazado en su discurso crítico sobre la obra de Hernández, acerca de una historia nacional que no ha logrado superar los conflictos de miseria, injusticia y deshumanización planteados en el Martín Fierro -acaso porque dicha historia se ha narrado bajo el supuesto de que ya desaparecieron-, Martínez Estrada no plantea una alternativa personal clara y constructiva. En su fino pero amargo ensayo de interpretación se advierte más un deseo de evasión hacia un mundo imaginado, construido a la medida de soñadores utopistas, que una confrontación directa y concreta con el problema metafísico - pero también ideológico y políticode la «realidad superpuesta». En todo caso, la fuga hacia un mundo descontaminado de ruina moral y descomposición social ya la había preparado el autor, pocos años antes de la segunda edición de Muerte y transfiguración, en El mundo maravilloso de Guillermo Enrique Hudson (1951).

En su semblanza poética, henchida de lirismo y nostalgia bucólica, del autor anglo-argentino de La tierra purpúrea, Martínez Estrada acomete la defensa de un mundo incontaminado por la técnica y la sociedad modernas. Se trata, con ese «mundo

16 Esta mención a los «problemas indígenas» en el ambiguo texto estradiano viene a propósito para subrayar, siquiera de forma muy breve, el siguiente punto que viene a la mente después de leer un pasaje de M.S. Stabb. Según este autor, la «premisa fundamental» del pensamiento estradiano es extremadamente simple, se trata de la conocida idea rousseauniana sobre la bondad natural del ser humano que el advenimiento de la convivencia civilizada viene a corromper. Así, en consonancia con esta idea, su Muerte y transfiguración «está construido sobre las proposiciones de que el gaucho era bueno por naturaleza; que el régimen civilizador de Sarmiento lo corrompió primero y lo destruyó después, y que al cabo del siglo apareció una complicada mitología nacional destinada a falsear el carácter del gaucho auténtico al tiempo que ocultaba el crimen de su destrucción» (Stabb, 1969, p. 268). Esta interpretación, válida quizá en términos generales para el caso del gaucho, debería complementarse, sin embargo, con la mención de que nociones como «bárbaro» o «salvaje» han tenido en la cultura occidental -como lo ha mostrado, entre otros, H. White (1978) -, una historia ideológica más complicada y enrevesada en su mezcla de connotaciones positivas y negativas. Lo cierto es que, sin poder entrar aquí en los detalles de la discusión, la posición estradiana sobre el tema indígena no resulta, en muchos casos, enteramente clara e inequívoca. 
maravilloso», de una realidad alternativa que de nuevo se sobrepone al del -según la opinión estradiana- caos político y demagogia social de los años cincuenta del siglo pasado en Argentina. En medio del peronismo, la auténtica bestia negra de Martínez Estrada, su exposición se complace, en El mundo maravilloso, como ha dicho un autor, en «la apología de una era pastoril desaparecida o acaso inexistente desde siempre», pero que en todo caso le sirve como criterio, aún más inflexible y severo, para medir los alcances del desbarajuste social de su propio tiempo ${ }^{17}$.

En su estudio crítico sobre la obra de Ezequiel Martínez Estrada, J.M. Rivera ha arribado a dos conclusiones tan acertadas como contrapuestas. Por un lado, según ese autor, el problema de la obra ensayística crítica de Martínez Estrada «consiste en haberse perdido en un laberinto creado por sus propias palabras; en haberle negado posibilidad a la mutante realidad; en haber aceptado la inmovilidad como ley de la historia» (1987, p. 45). Por otro lado, es indiscutible también que el «mayor mérito de la obra de Martínez Estrada estriba en haber retomado los temas de la nacionalidad, la historia, la sociedad y la literatura, problematizándolos y convirtiéndolos en objeto de una discordia duradera» (1987, p. 164). Para empezar, no parece problemático aceptar como válido, en términos generales, el segundo juicio, pues, en efecto, varias de las obras más importantes de Martínez Estrada plantean cuestiones harto relevantes aún hoy en día, sobre, por ejemplo, la relación entre arte y sociedad, o entre literatura y política.

Los problemas comienzan cuando se procede a examinar más de cerca los principales supuestos teóricos constitutivos del pesimista diagnóstico estradiano. Justo entonces se ven aparecer aspectos problemáticos de la cosmovisión estradiana, como el arriba señalado por Rivera en torno al compromiso estradiano con una inmutable ley histórica, lo que con otras palabras quiere decir, un compromiso con la idea de que la historia está constituida por ciertos rasgos invariables, irremediablemente repetitivos -otra forma de apelación al mito del eterno retorno- que no admiten modificación o progreso. Las implicaciones derrotistas de semejante punto de vista parecen demasiado evidentes como para ameritar ulterior explicación. ¿Qué posibilidades de reacción o que espacios constructivos permite imaginar el pensamiento de Martínez Estrada ante este proceso sobrehumano de falseamiento de la realidad, de su reemplazo por otra de rasgos puramente «literarios» que sin embargo fue, a su vez, despojada de su carácter «subversivo»?

${ }^{17}$ El tono altamente crítico de su estudio, no es obstáculo para que J.M. Rivera reconozca que «Hudson es el mejor poema de Martínez Estrada [...] Hudson es, desde el punto de vista del estilo, la obra mejor concebida de cuantas escribiera Martínez Estrada" En ella «se concatenan las defensas de tres mundos: el agreste o preindustrial-antiurbano; el de la niñez y el de los animales (especialmente el de las aves). Entrar el universo de Hudson, es sumergirse en agua de rosas. Para Martínez Estrada es un acto de purificación» (1987, pp. 50-51). 
Como ya se dijo, la propuesta terapéutica estradiana dista mucho de ser clara o coherente. En ocasiones, Martínez Estrada parece apoyar-retomando la idea de Max Scheler- la recuperación de una cierta «sabiduría empírica», contenida en el Martín Fierro, muy diferente del mero saber técnico o científico. Para él, esta sabiduría esencial que guarda el texto es «de la calidad del saber universal y eterno de los pueblos, y no creo que la haya de más fecunda y cierta especie. Porque al saber científico, técnico, sistemático se opone ese saber abierto, de metáforas, de fluir y sentir con las mismas cosas que acaecen en la vida» (I, p. 403). Estas poéticas apelaciones a la sabiduría del pueblo - esa «flor de la humanidad»-, bellamente construidas pero demasiado vagas, se revelan bien pronto como del todo ineficaces cuando, según el mismo Martínez Estrada, se mide su poder con el de las fuerzas telúrico-metafísicas que mantienen en estado de postración moral y social a la nación argentina.

No menos ambiguas resultan las elucubraciones estradianas sobre el ámbito fundamental de lo político. Es obvio que la preocupación principal en obras como Radiografía de la pampa y Muerte y transfiguración era recuperar para sus contemporáneos el sentido de la realidad del que han sido despojados, según Martínez Estrada, en parte por sus gobernantes, en parte por esas mismas enigmáticas fuerzas telúricas actuantes a través de (ciertas) obras literarias. Pero el problema es que sus admoniciones no tienen contenido ni destinatario claros. Porque, ¿quiénes son los llamados a efectuar, aun si fuera posible, el cambio radical imaginado y sobre qué base teórica?

Aún peor resulta el hecho, señalado por varios intérpretes, de que Martínez Estrada no parece interesado en el diálogo para llegar al menos a consensos razonables, a resultados imperfectos pero con todo realizables en la medida de lo humanamente posible. La postura personal de Martínez Estrada -sobre todo en su etapa de mayor rabia antiperonista- lo muestran como un intelectual más bien intolerante, que reitera en forma intransigente un mensaje despectivo y desalentador. A veces pareciera que acepta de buena gana el papel de inquisidor intocable, cubriéndose las espaldas con el escudo formidable del fatalismo histórico-telúrico. ¿Es que acaso el autor de Muerte y transfiguración habría albergado alguna esperanza de convencer a aquella «chusma» de «descamisados» peronistas -a la que ataca por su devoción ciega al líder populista-, que su lectura del Martín Fierro es la única que les puede quitar la venda de los ojos, la única que les permitirá ver la historia de su país como realmente es, un compendio de mentiras y manipulaciones, una historia que en realidad es una realidad compuesta desde el reino de la poesía? ${ }^{18}$

18 Todo esto se lo ha recriminado incluso un biógrafo tan comprensivo como P.G. Orgambide, quien, refiriéndose al antiperonismo furibundo de ¿Qué es esto?, apunta, entre muchas otras críticas: «...En ¿Qué es esto? Martínez Estrada monologa, discute con su pueblo, sintiéndose juez y parte de su reciente drama político: el peronismo, las causas que a su juicio lo determinaron, el problemático presente. Pero no entabla el diálogo, la realidad que enfrenta es proyectada a veces caprichosamente, desarticulada por esa visión individualista, por momentos unamunesca, de Martínez Estrada» (1997, p. 155). Igualmente Sebreli, en su estudio, tan implacable como imprescindible sobre el pensamien- 
Pero, si ni la vaga apelación a la «sabiduría empírica» ni la igualmente ingenua exhortación a un cambio de mentalidad moral y político resultan propuestas viables para el enfrentamiento de la crisis nacional argentina, ¿qué le queda a Martínez Estrada excepto sumirse en la nostalgia por los mundos maravillosos de Hudson o los bosques impolutos de Thoreau? Colocado en las antípodas del ideal civilizador sarmientino -ideal en todo caso, por otras razones, igual de cuestionable-, Martínez Estrada hizo un último intento, a buen seguro sincero y quizá no tan extraño después de todo, por acomodar su pensamiento y personalidad individualistas a las exigencias de tareas colectivas mucho más concretas y complicadas en el marco de la Revolución cubana. No sorprende que al final dicha experiencia le haya dejado un sabor agridulce al autor argentino. Porque, ya sea proyectando evasiones hacia universos sublimes, poblados de hombres ejemplares en medio de ecologías edénicas, o ya sea asumiendo un voluntarismo político-utopista extremo, Martínez Estrada parece que no fue capaz de complementar sus lamentaciones sobre los problemas de su país y de su época con indicaciones constructivas pero balanceadas, corajudas pero sensibles al hecho de la imperfección humana. Propuestas, en fin, que no fuesen finalmente descalificadas por su carencia de sentido de la realidad.

La idea de que ciertos textos literarios -como el Martín Fierro en forma ejemplarson capaces de producir formas alternativas de realidad que se superponen y acaban por suplantar, con la complicidad de grupos dirigentes y minorías intelectuales corruptos, la realidad histórica, constituye un ejemplo claro de lo que es capaz de dar de sí, para bien y para mal, el ensayo estradiano. Asimismo, la presencia del tema de la «realidad superpuesta» en Muerte y transfiguración descubre lo que se puede encontrar en los dos planos fundamentales en que se bifurca el aporte intelectual y artístico de Martínez Estrada. En el del manejo del lenguaje, las exquisiteces de un prosista admirable, sin duda uno de los mejores estilistas de lengua española, dueño de una capacidad líricoexpresiva fuera de serie. En el plano de las ideas, la propensión a oscilar entre el aporte de reflexiones lúcidas y valientes - por ejemplo, sus críticas a las ideologías fascistas-, enriquecidas con una inusual sensibilidad poética, y la insistencia en defender posiciones demasiado cercanas al irracionalismo y al fatalismo histórico, posiciones que con frecuencia van en menoscabo, socavándola, de la sutileza analítica.

\section{BIBLIOGRAFÍA}

Borges, J.L. (1997). Discusión. Madrid: Alianza.

Hernández, J. (2007). El gaucho Martín Fierro. La vuelta de Martín Fierro. Madrid: Cátedra.

to estradiano, afirma: «Desde lo alto de la montaña y muy cerca del cielo, adonde se había retirado, Martínez Estrada increpaba al pueblo argentino: a los estadistas, a los maestros, a los estudiantes, a los patrones, a los obreros, a los militares, a los sacerdotes, a los jueces, a los escritores [...] Era el eterno incomprendido por su público. En ningún momento pensaba que, a su vez, el público podía sentirse incomprendido por él» (2007, pp. 135, 138). 
Martínez Estrada, E. (1995). El hermano Quiroga. Cartas de Quiroga a Martínez Estrada. Caracas: Biblioteca Ayacucho.

- (1993). La literatura y la formación de la conciencia nacional. En L. Zea (comp.), Fuentes de la cultura latinoamericana II (pp. 13-35). México: FCE.

- (1958). Muerte y transfiguración de Martín Fierro. Ensayo de interpretación de la vida argentina. 2 volúmenes. México \& Buenos Aires: FCE.

- (1956). Literatura y vida. Consultado: 3.05.09, de http://www.ensayistas.org/filosofos/argentina/ eme/eme10.htm

- (1945). Carta a Victoria Ocampo. Consultado: 3.05.09, de http://www.ensayistas.org/filosofos/ argentina/eme/eme3.htm

Mead Jr., R.G. (1956). Breve historia del ensayo hispanoamericano. México: Ediciones de Andrea.

Orgambide, P.G. (1997). Un puritano en el burdel. Ezequiel Martínez Estrada o el sueño de una Argentina moral. Rosario: Ameghino.

Oviedo, J.M. (1991). Breve historia del ensayo hispanoamericano. Madrid: Alianza.

Rama Á. (1977). El sistema literario de la poesía gauchesca. En J.B. Rivera (comp.), Poesía gauchesca (pp. IX-LIII). Caracas: Biblioteca Ayacucho.

Rivera, J.M. (1987). Estética y mistificación en la obra de Ezequiel Martínez Estrada. Madrid: Pliegos.

Sarmiento, D.F. (1977). Facundo o Civilización y barbarie. Caracas: Biblioteca Ayacucho.

Stabb, M.S. (1969). América Latina en busca de una identidad. Modelos del ensayo ideológico hispanoamericano, 1890-1960. Caracas: Monte Ávila.

Sebreli, J.J. (2007). Martinez Estrada. Una rebelión inútil. Buenos Aires: Sudamericana.

Skirius, J. comp. (2004). El ensayo hispanoamericano del siglo XX. México: FCE.

White, H. (1978). Tropics of Discourse. Essays in Cultural Criticism. Baltimore \& London: The Johns Hopkins University Press. 